\title{
Disturbed left ventricular inflow and ejection pattern in corrected atrioventricular septal defect patients assessed by 4DFlow MRI and particle tracing
}

Emmeline Calkoen ${ }^{1 *}$, Patrick J de Koning ${ }^{2}$, Rob J van der Geest ${ }^{2}$, Albert de Roos ${ }^{2}$, Arno Roest ${ }^{1}$, Jos J Westenberg ${ }^{2}$

From 18th Annual SCMR Scientific Sessions

Nice, France. 4-7 February 2015

\section{Background}

The normal pattern of left ventricular (LV) inflow and ejection of affects the efficiency of cardiac pumping performance. Altered inflow direction due to a corrected atrioventricular septal defect (AVSD) may disturb this pattern leading to decreased efficiency. We aimed to quantitatively describe the LV blood flow pattern using 4-dimensional velocity-encoded cardiac magnetic resonance imaging (4DFlow MRI) and particle tracing in healthy volunteers and corrected AVSD patients.

\section{Methods}

32 patients (age $25 \pm 14$ years) and 30 healthy volunteers (age $26 \pm 12$ years) were included. Whole-heart 4D Flow MRI was performed on 3Tesla MRI with free breathing, three-directional velocity encoding of $150 \mathrm{~cm} / \mathrm{s}$ in all directions, spatial resolution $2.3 \times 2.3 \times 3.0-4.2 \mathrm{~mm}^{3}$ and 30 phases reconstructed over one cardiac cycle. At end-diastole the LV was evenly filled with particles and subsequently tracked by backward and forward particle tracing to analyze the LV 4-componental flow as introduced by Eriksson [JCMR, 2010] discriminating 1. direct flow entering and leaving the LV within one cycle, 2 . retained flow entering during diastole but remaining in LV during next systole, 3 . delayed ejected flow already in LV before diastole and leaves LV during systole 4. residual volume. Regurgitant flow in patients was added as a fifth component. The path of inflowing particles (i. e. direct and retained flow) during diastole was evaluated using the AHA 16-segment LV cavity model.

${ }^{1}$ Pediatric Cardiology, Leiden University Medical Center, Leiden, Netherlands Full list of author information is available at the end of the article
Difference in componental percentage and in particle percentage (pp; amount of particles per segment as percentage of the sum of particles) between patient and controls were compared using unpaired t-tests.

\section{Results}

Patients showed a smaller percentage of direct flow compared to volunteers $(30 \pm 9 \%$ versus $44 \pm 11 \%$, $\mathrm{p}<0.001)$ and larger percentage of delayed ejected flow ( $22 \pm 6 \%$ versus $17 \pm 7 \%, \mathrm{p}=0.004)$ and residual volume (21 $\pm 7 \%$ versus $16 \pm 6 \%, \mathrm{p}=0.002$ )(Figure 1 ). In the $L V$ apex a similar pp of direct flow ( $4 \pm 4 \%$ versus $4 \pm 4 \%, \mathrm{p}=0.96$ ), but significantly higher retained flow $(7 \pm 4 \%$ versus $5 \pm 2 \%, \mathrm{p}=0.009)$ was observed. In the mid-lateral segments, decreased pp of direct flow $(13 \pm 5 \%$ versus 16 $\pm 5 \%, \mathrm{p}=0.015)$ and increased retained flow $(11 \pm 4 \%$ versus $7 \pm 4 \%, \mathrm{p}<0.001$ ) was observed (Figure 2 ).

\section{Conclusions}

Particle tracing and 4DFlow MRI enable quantitative assessment of altered LV filling and ejection patterns after AVSD correction, with less direct flow and more residual volume in patients versus volunteers, and an increase in (retained) flow directed to the mid-lateral and apical segments, which may contribute to a decreased cardiac pumping efficiency.

\section{Funding}

E.E. Calkoen is financially supported by a grant from the Willem-Alexander Kinder- en Jeugdfonds, J.J.M. Westenberg is financially supported by a grant from the Dutch Technology Foundation (STW), project number 11626. 

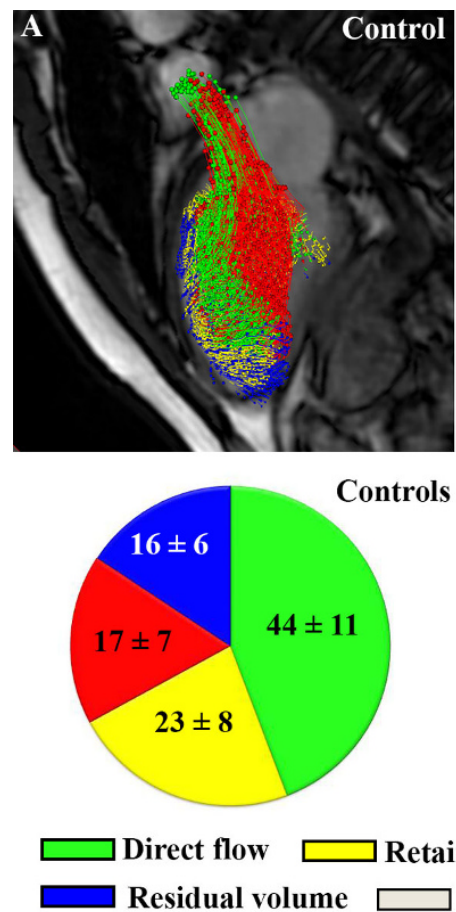
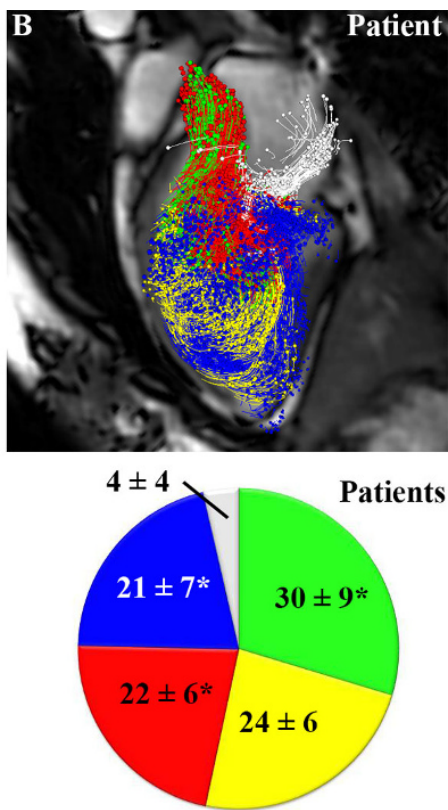

Retained inflow

\section{Delayed ejection} Regurgitant volume

Figure 1 Example of a control and patient at an early systolic phase. Pie chart presents component percentage of left ventricular flow, with * indicating $P<0.01$. Direct flow enters and leavs the LV within one cycle. Retained flow enters during diastole but remains in LV during next systole. Delayed ejected flow is already in LV before diastole and leaves LV during systole. Residual volume remains in LV during whole cardiac cycle. Regurgitant volume contains blood entering the left atrium during systole.


$\square$ Direct flow $\square$ Retained inflow $\square$ Delayed ejection
Residual volume $\square$ Regurgitant volume

Figure 2 Particle tracing during diastole in a control (A and B) and a patient ( $C$ and $D)$, with in B and D more lateral and apical flow contribution of particles belonging to the retained flow. 


\section{Authors' details}

${ }^{1}$ Pediatric Cardiology, Leiden University Medical Center, Leiden, Netherlands.

${ }^{2}$ Radiology, Leiden University Medical Center, Leiden, Netherlands.

Published: 3 February 2015



Submit your next manuscript to BioMed Central and take full advantage of:

- Convenient online submission

- Thorough peer review

- No space constraints or color figure charges

- Immediate publication on acceptance

- Inclusion in PubMed, CAS, Scopus and Google Scholar

- Research which is freely available for redistribution

Submit your manuscript at www.biomedcentral.com/submit 